\title{
Rendering beyond_words in transitioning to motherhood through visual and dramatic arts
}

\author{
Victoria Scotti ${ }^{1 *}$, Nancy Gerber ${ }^{2}$ \\ 1 Independent Scholar and Author, Art Therapist \\ 2 Program in Creative Arts Therapies, Drexel University. \\ *victoriascotti@gmail.com
}

Received: 23 May 2017 ; Accepted: 29 September 2017 ; Published: 1 November 2017

Editor: Michael Viega Reviewer: Carolin Kenny

\begin{abstract}
The purpose of this doctoral dissertation research study was to use arts-based research methods to explore the beyond_words phenomena of first-time mothers who were in the process of transitioning to motherhood. The multidimensional embodied, emotional, and sensory experiences that accompany new motherhood can be overwhelming, be difficult to articulate verbally, and impact the perceptions of the new mother's relationship to herself and her child (Crossley, 2009; Lintott \& SanderStaudt, 2011; Prinds et al., 2014).

In order to honor and capture the emergent, vital, and multi-dimensional nature of beyond_words in transitioning to motherhood, in this study, arts-based research methods were used to explore and represent these phenomena, otherwise inexpressible in words. The arts-based results are presented as five portrait syntheses and a final synthesis play in four acts that bring to life and invite the viewer to live the mothers' beyond_words experiences, while simultaneously positioning them within the wider context of current medical and health sciences research perspectives.

The final synthesis, which is the featured dramatic play, aspires to give voice and aesthetic power to these mothers' beyond_words transitioning to motherhood experiences. In the philosophical tradition of ABR (Leavy, 2009, 2015), this study marries the rigor of research with the aesthetic power of the visual and dramatic arts challenging existing assumptions, beliefs, and cultural stereotypes about motherhood and disseminating the results to relevant stakeholders.
\end{abstract}

Keywords: art therapy, transitioning to motherhood, arts-based research, portraiture

\section{Introduction}

This arts-based research study explored the beyond_words phenomena for women transitioning to motherhood. Beyond_words is defined as the aesthetic pre-verbal and preconscious phenomenon including sensory, embodied, emotional, and imaginal ways of knowing that women encounter when they become mothers. These multi-sensory, embodied, and emotional experiences permeate and powerfully influence the mother's body and mind, impacting her perceptions of and relationships with her child and family. In addition to the implosion of intrinsic bodily and emotional stimuli, new mothers are also exposed to stereotypic images and narratives about motherhood in the media 


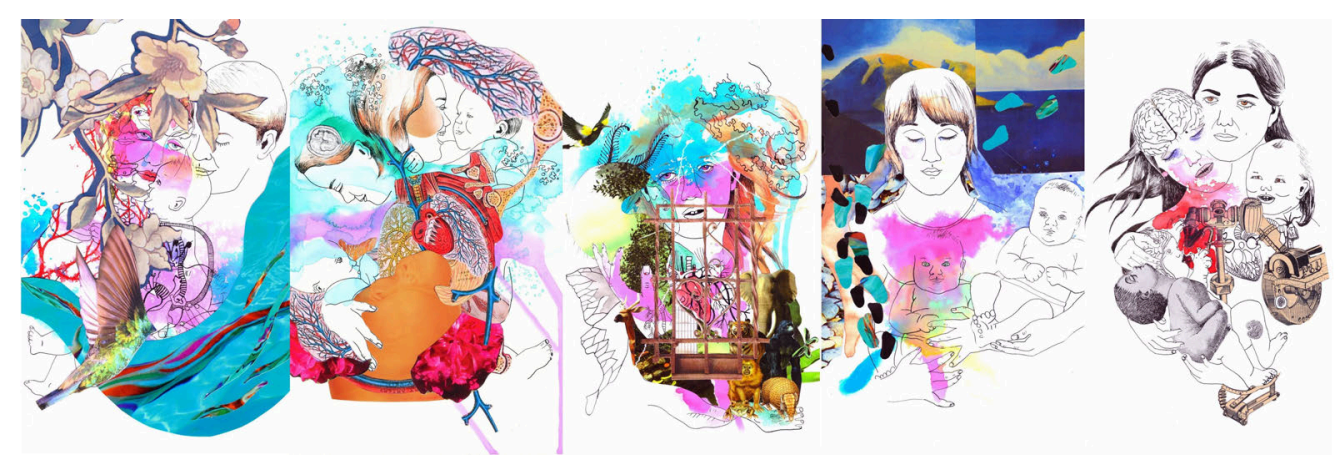

Figure 1

that can conflict with those beyond_words experiences in the emerging self-image of the new mother (Cowdery \& Knudson-Martin, 2005; Darvill et al., 2010; Fahey \& Shenassa 2013; Razurel et al., 2011).

Due to the epistemic nature of the beyond_words phenomena, their under-representation in the dominant culture, and, their incompatibility with more traditional methods of research, we decided to use an arts-based research approach by which to represent and authenticate the beyond_words phenomena experienced by new mothers. The arts-based interpretations and representations of these phenomena provide a venue by which new mothers can understand and affirm their own experiences as well as to communicate and disseminate these insights to a larger social context to increase cultural empathy and understanding.

The purpose of this article, therefore, is to present the arts-based results of this research project and its message for new mothers and beyond. Traditionally the artsbased representation of results in ABR studies, such as the play presented in this article, is intended to stand alone as a work of art. However, for purposes of contextualization and in the service of the advancement of knowledge about ABR, a contextual description of the topic and a textual description of the investigational methods and procedures resulting the final synthesis performance are also included in this article. In addition to demonstrating the topical rationale and rigor of the methods, the contextual and procedural descriptions simultaneously act as a map to guide reader engagement with the arts-based results. To that end in the text we: 1) provide a concise contextual description about the beyond_words phenomena in transitioning to motherhood, 2) briefly introduce montage portraiture, the ABR method that was specifically designed for this study, 3) provide the reader a guide to engagement with the artsbased results of this study.

\section{Contextual Description}

The focus of this study was on the beyond_words phenomena in transitioning to motherhood. Beyond_words for the purpose of this study was conceptualized and operationally defined as the pre-verbal and unconscious sensory-embodied, relational, and imaginal phenomena that are inherent in all dimensions of transitioning to motherhood. The problem that this study addressed was twofold. First, because of the sense-based and embodied epistemic of beyond_words experiences are unconscious; they pose a challenge in translation to verbal expression and thus remain generally unarticulated by the mother (Crossley, 2009, 1991; Lintott, 2011; Prinds et al., 2014). When becoming a mother, a woman encounters multiple dynamic rewarding, challenging, and transformative experiences that exist within interactive physiological, psychological, social, and spiritual domains. The beyond_words phenomena are embedded within these domains and are representative expressions of the multidimensional experience of transitioning to motherhood. Based upon the contextual and conceptual evidence that these transitioning to motherhood phenomena can potentially exert a strong, insidious influence on the woman's self-image, affecting her relationship with her child and fam- 
ily across multiple domains; further investigation, articulation, and dissemination is warranted (Afoakwah et al., 2013; Nelson, 2006; Or, 2010; Schmied \& Lupton, 2001; Prinds et al., 2014).

The second aspect of the problem was related to the selection of a research philosophy and methodology that would capture the beyond_words phenomena while addressing the under-representation of these phenomena in the dominant research literature and culture. Due to the aesthetic epistemic of beyond_words, using traditional quantitative or text-based research methods was determined to be ill-aligned epistemologically, thus making it prohibitive. Therefore, the decision was made to use an arts-based and art therapy informed research approach. Using an art therapy and arts-based research informed philosophy and method, we aspired to explore ways in which the new mother could identify, express, and make meaning of her beyond_words experiences while simultaneously creating an emotional, visual, and verbal language to represent these experiences. Ultimately we hope to contribute to the conversation and accessibility of resources for new mothers, their families, and the general public by offering resonant transformative visual and dramatic representations of the multifaceted and beyond_words experience of transitioning to motherhood.

To this end the intention is to disseminate the arts-based, descriptive written, and performative results representing women's beyond_words of transitioning to motherhood experiences to the following groups: 1 ) the mothers-participants, new mothers, and mothers-to-be to contribute to their awareness and validation of beyond_words experiences in transitioning to motherhood; and 2) to art therapists and other clinicians who work with new mothers and couples. For art therapists and other clinicians, the aim of the results of the study was to increase awareness of the beyond_words experiences during the mother's transition, foster empathy with new mothers during this transition, and provide a practical clinical paradigm that might be used in their work with new mothers.

The research question for this study was two fold: 1) How do first-time mothers express and make meaning of their beyond_words experiences, and 2) how are these experiences represented using montage portraiture?

\section{Situating the researcher- personal stance}

The worldview of this study is influenced by the first author's (Scotti) lived experience as a mother, art therapist, and a visual artist. Becoming a mother 9 years ago was a life changing experience for me. Particularly the first year of transitioning to motherhood prompted me to wonder about the boundaries between the self and the other, my identity as a person and a mother, and the complexity of the maternal experiences. It occurred to me that some of these maternal experiences were beyond_words: they were embodied, relational, not fully conscious, fluctuated on the continuum of pleasure and pain, and were very difficult to articulate and make meaning of verbally. As an art therapist, I use art making and verbal follow-up to explore human experiences with my clients. As an emerging arts-based researcher, I designed an independent pilot study where I used self-portraiture to explore my own embodied experiences as a mother and journaled about my thoughts and feelings that came up during the process. This exploration opened a door to explore beyond_words experiences in transitioning to motherhood, which resulted in greater self-awareness, creative growth, and a clear direction for my research.

\section{The Design and Method}

\section{Design}

The design of this study was arts-based research. Arts-based research or ABR has been defined as "an effort to extend beyond the limiting constraints of discursive communication in order to express meanings that otherwise would be ineffable" (Barone \& Eisner, 2012, p. 1). ABR provides a framework for the rigor and systematic inquiry of 
research while honoring the ontological and epistemological foundations of the phenomena under investigation. The methods of ABR, in keeping with these philosophical traditions, embrace and prioritize the use of artistic practice in all phases of the research (McNiff, 2008). In this study visual and dramatic arts practices were used to examine and represent the beyond_words phenomena in transitioning to motherhood.

To honor and capture the emergent phenomenon of beyond_words in transitioning to motherhood, this study has been situated within the art therapy informed, arts-based research paradigm (Chilton, Gerber, \& Scotti, 2015). The arts-based research paradigm is one that embraces a pluralistic, intersubjective ontology wherein intersections between individual realities yield a co-constructed human narrative. This human narrative is often comprised of knowledge that is pre-verbal or unconscious. This form of knowledge, as referenced previously, includes sensory, embodied, emotional, and imaginal cognitions, which together form what we call an aesthetic epistemology. The pluralistic intersubjective ontology and the aesthetic epistemology define the nature of the beyond_words phenomena that is the subject of this investigation.

This arts-based research study aspired to assist the research participants to express and make meaning of their beyond_words experiences of transitioning to motherhood using both artistic means as well as verbal reflection that are the basis of both art therapy and arts based research practices (Kapitan, 2010; Leavy, 2009). The study was approved by the Institutional Review Board of Drexel University.

\section{Methods}

The arts were central to the investigation, interpretation, and representation of the beyond_words phenomena of transitioning to motherhood. Therefore, data generation and analysis required engagement in the arts from the participants and the researcher during every phase of the research. Five women who met the criteria of transitioning to motherhood volunteered to participate in this study. A special method for data generation and analysis called Montage Portraiture was designed specifically for this study by the primary author. The method builds on the concept of portraiture, a genre that is used both in the fine arts (Brilliant, 2002; Freeland, 2010; West, 2004) as well as qualitative research (Lawrence-Lightfoot, 2005; Lawrence-Lightfoot \& Davis, 1997) and art therapy practice (Alter-Muri, 2007; Costello-Du Bois, 1989; Halifax, 2003; Fish, 2012; Hanes, 2007; McGann, 2006)

In Montage Portraiture, the data generated included textual interview data, participant generated artwork, researcher generated arts based memos, researcher generated in depth arts-based analysis, and participant feedback. In the Montage Portraiture is a visual/textual interview in which the participants were asked to create a self-portrait by tracing photographs of themselves and their child. During the interview they added drawings to their portrait as they verbally described and reflected on the artwork while exploring their beyond_words experiences in transitioning to motherhood. Data generation also included artistic and written reflexivity from the researcher in response to the visual and textual data generated in the Montage Portraiture interview. In the data analysis phase, the researcher used her personal artistic practice to create montage portraits of the individual participants based on careful content analysis of the textual and visual data to authentically capture, reflect, and represent their experiences. The portraits were shared with the participants to obtain their feedback. Finally, the Final Synthesis was created by creating an aggregate group portrait and a cross case analysis. The Portrait Syntheses and the Final Synthesis were exhibited and performed on the premises of Drexel University in Philadelphia. External input was collected from the audience to obtain feedback and to evaluate the credibility of the arts based results.

\section{The Arts-based Results}

In this study there were two major arts-based results-the Portrait Synthesis and the Final Dramatic Synthesis. In the Portrait Synthesis, the visual arts were used to con- 

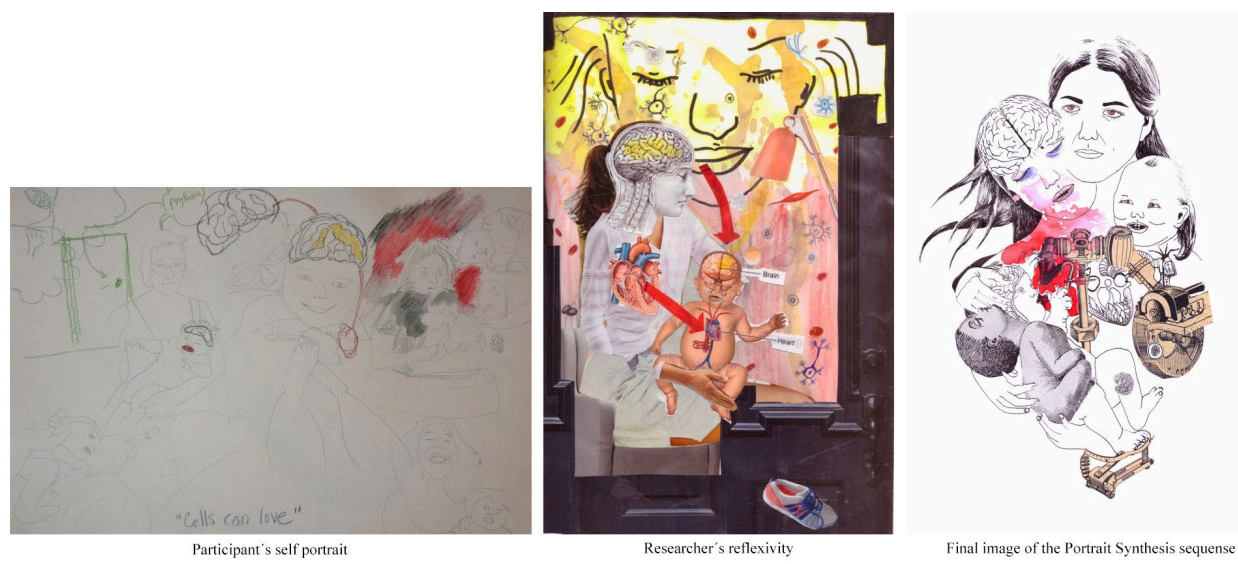

Figure 2. The creation of Gabriela's Portrait Synthesis

struct portraits of each woman using her words, her self-generated montage portrait, the researcher's memos, and the researcher's visual art interpretation, participant feedback, synthesis, and representation of these data.

The Final Dramatic Synthesis is the arts-based result of the study in dramatic play form. This play which is the focus of this article, represents the aggregate of the artsbased and narrative data from five participants individual Portrait Syntheses in a group interactive dramatic portrayal. Even though the final synthesis is the focus of this article, it is essential to also describe and include the individual portrait syntheses. We cannot reproduce these 5 portrait syntheses here in full so we will present one case in order for the reader to understand how the research data and analysis from each case were synthesized and represented in the final synthesis.

\section{Portrait Synthesis}

In order for the reader to quickly grasp how the artistic images in Portrait Synthesis emerged from the original data, it is useful to juxtapose the images that the participants and the researcher created during data generation, and the final image of the Portrait Synthesis, as seen in the case example of one of the five participants, Gabriela. The first of the set of the three images represent the initial artistic data collected from the participant, Gabriela. The second image features arts based memoing responses by the researcher. The third image is the final image of the Portrait Synthesis that demonstrates how the researcher systematically synthesized the textual and image based data to create the Portrait Synthesis for Gabriela.

In order to represent the investigative and representative integrity of arts-based research in this project, we share an example here of one Portrait Synthesis from one participant (Gabriela). The Portrait Synthesis is presented as if it were a journal of Gabriela's experiences as a new mother aligning the visual representation with the narrative description from the visual and verbal interview data. The captions that appear in red mark the verbatim quotes from the participant.

\section{Portrait Synthesis}

\section{Participant 2: Gabriela}

August $2^{\text {nd }}$

Next month is Alison's first birthday. I can't believe it's been a year already! She's grown to be a happy, chubby, thriving baby. We are planning to celebrate at home with family and a few of for her little friends. As we are getting closer to the date, I want our home to be neat and clean for the party so I'm clearing the house of newborn onesies and toys that she has outgrown. The bassinet has to go, too! I've been a bit sentimental about it but rationally I understand that it's just taking up too much space and she won't fit in it any more. Wow, it feels like yesterday that she was sleeping in 
it, and now she's almost a year old. The first year is a milestone, and it all happens so fast from the time you deliver to now. I am glad that I can take this time to look back at my experience of becoming a mom.

(;)

Figure 3

Today at work, looking at some cell samples through the microscope, I realized that in the beginning Alison, too, was just a cluster of cells. How incredible is that!

Figure 4

It's really fascinating how tiny cells and biological processes can produce a living, breathing tangible human being ... 


\section{(;)}

Figure 5

I remember the day she was born. When I held her for the first time, I held her gently like an egg, because I was afraid she might just break.

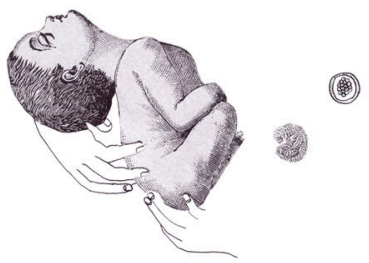

Figure 6

But then again, she was fragile but not that fragile. Babies are like animals, they are very resilient, they are just trying to survive. And I am responsible for her survival, for her to thrive. 


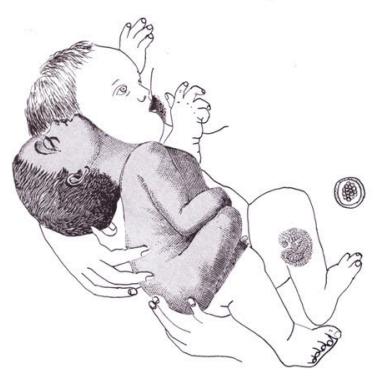

Figure 7

And she thrived on being breastfed. Ever since she was a newborn, Alison had a great appetite, I always breast fed her and am still breast feeding.

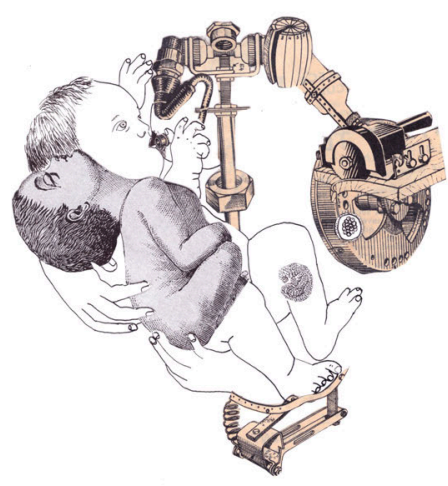

Figure 8

In the beginning, my whole life revolved around breastfeeding. My body became a feeding machine, I can almost envision the wheels and bolts and little mechanical parts to make milk every couple of hours. I was feeding and feeding and feeding... 


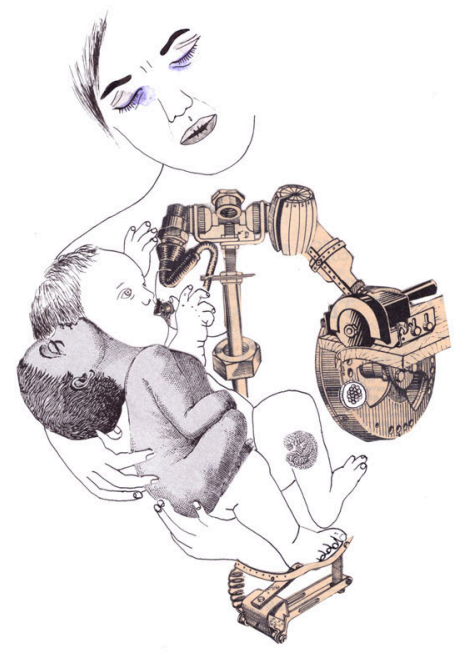

Figure 9

I usually cope pretty well with adversity but this was one of the hardest times in my life. I felt drained, truly. Words cannot even begin to describe how tired I felt.

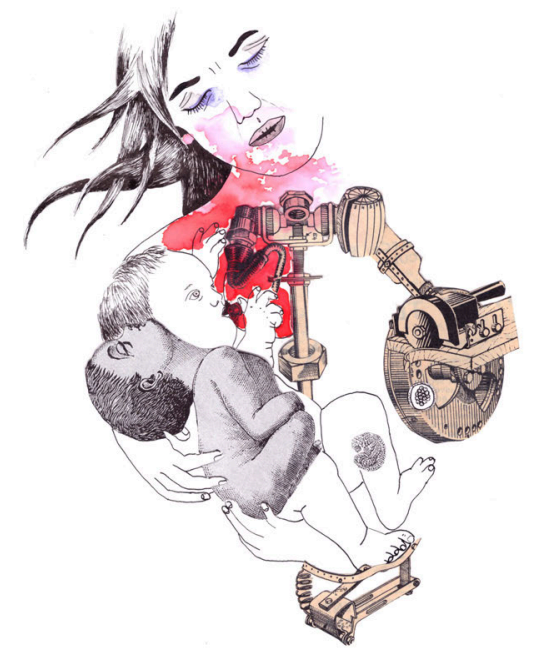

Figure 10

Plus, I had no life any more: I could not go out, and do what I wanted to do any more. I think that emotionally and physically probably breast feeding is one of the hardest things I've ever done. This time for me was all red and black. 


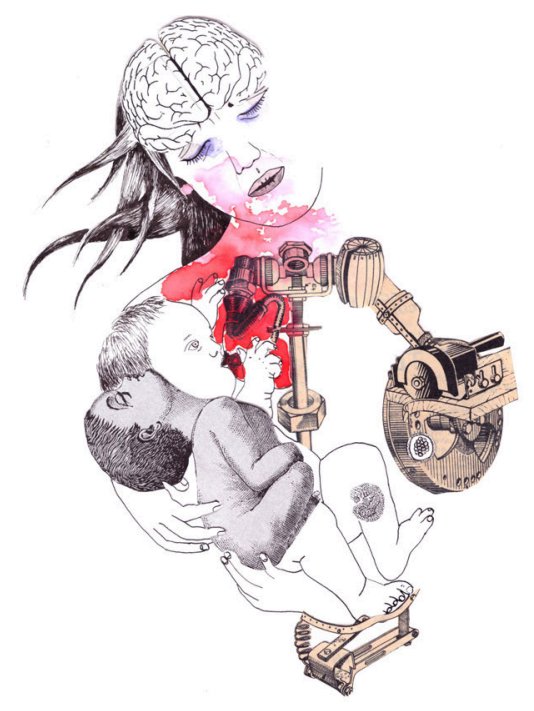

Figure 11

But then again, at some point you don't complain about it either because ... it's just a part of it. I am a pretty rational person who keeps emotions at bay and does not fantasize too much but...

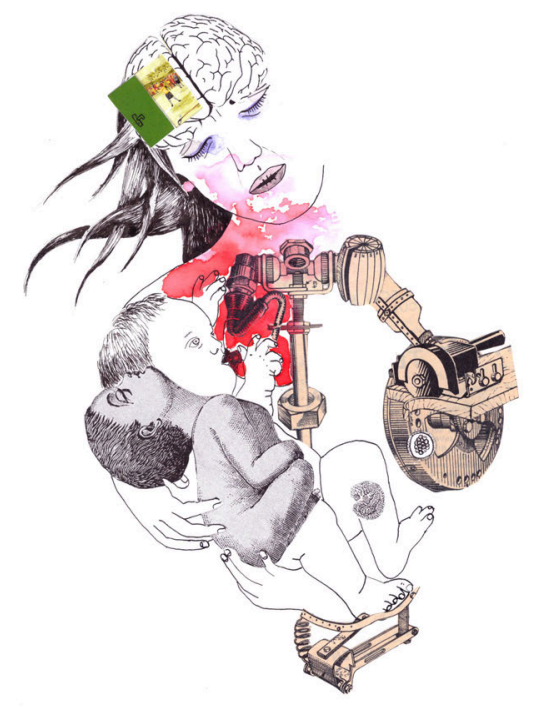

Figure 12

...I remember that sometimes after another sleepless night I had this fantasy of opening the door and going back to the life that I had: I imagined I could do ANYTHING: go to the gym, go out, go for a run...but I knew that it was not possible. Now that she is sleeping better, things are becoming easier and easier but the beginning was hard. 


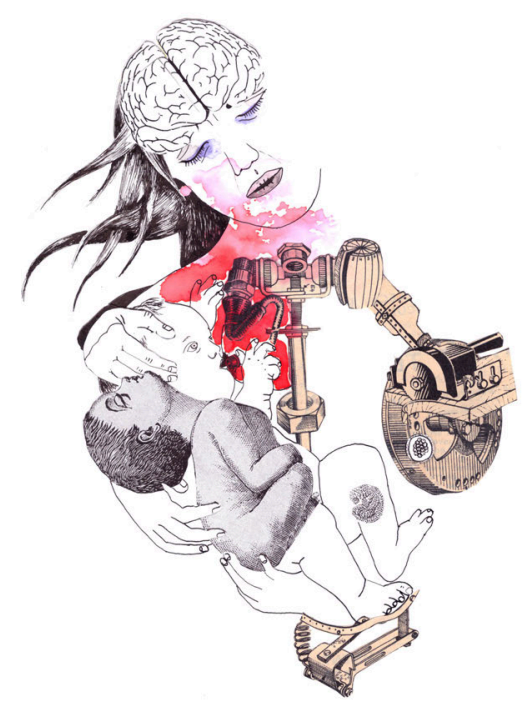

Figure 13

I really don't know how I would have gotten through this without my husband. I am so grateful to Eric who was so supportive and did everything he could to help. Just his arm around me at that time made feel supported and understood...

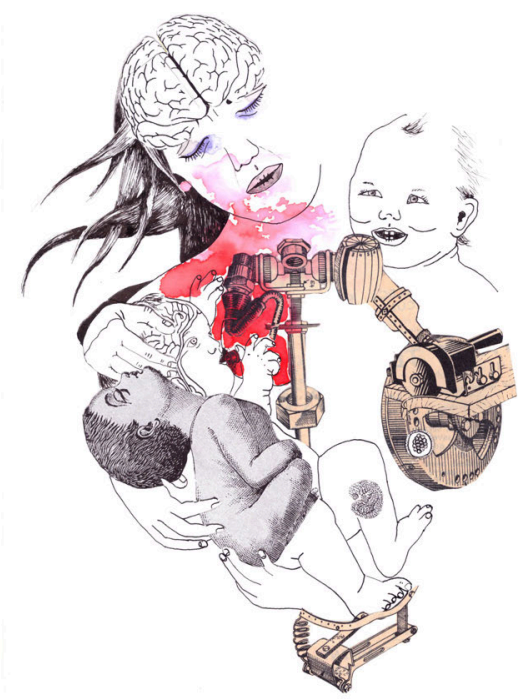

Figure 14

Now that Alison is almost a year old, I wonder if it's time to start weaning her. Breastfeeding has been so central in our relationship both physiologically and emotionally. At first, it definitely was a one-way relationship. I think I was just a source of food for her. Her brain was just wired for survival and the brain cells and instinctual processes were telling her what to do to get fed and get her needs met.

I'm holding this little baby that is just like a little animal trying to survive and I feel that I am exhausted but I have the obligation to feed her. You give and you give and you don't know if you get anything back ... but at some point you think it's worth it, it's working. I' m just feeding and feeding but she's thriving. 


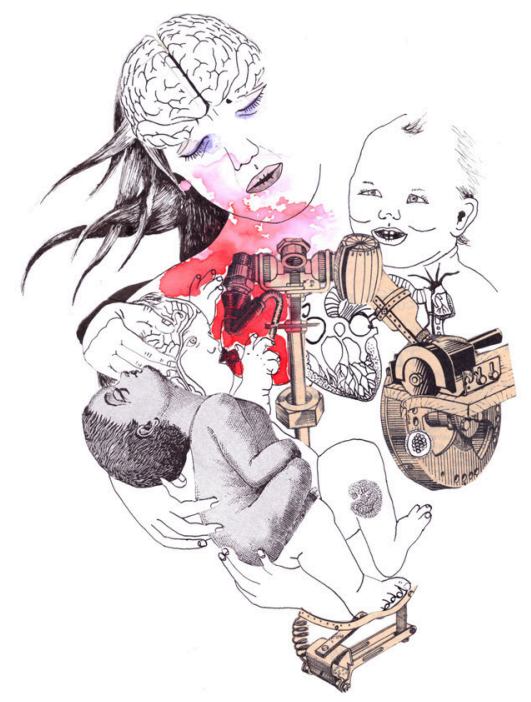

Figure 15

As she grows older, our relationship is evolving and getting more complex. Because she is developing more into someone who recognizes me as a person more than a source of food, I make a connection to her heart. She has a brain, hopefully she'll develop more of an attachment to the person more than the physiological need. Which is what matters. At the end.

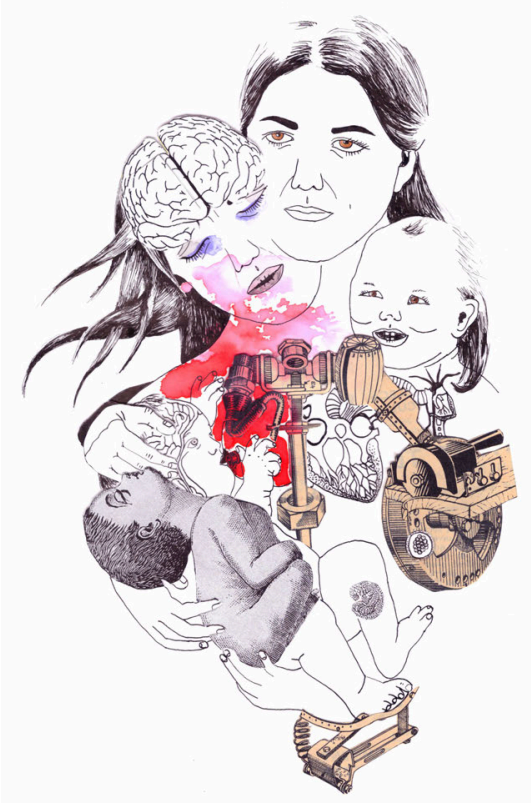

Figure 16

As she is developing and becoming more of a person of her own, I feel that I, too, am developing and growing as a mother and a person. I am confident as a mother, I know what I want and how to get things done. Happiness is the key word to sum up my experience of becoming a mom. I am happy with my relationship to Alison, and I think that I have coped well with adversity. I am so pleased that she is a thriving, happy baby.

As I am reading what I just wrote, I realize that the first weeks and months of transitioning to motherhood feel more and more distant, almost like looking at someone else's experience. With Alison's first birthday, we are celebrating the closing of a very important chapter in our lives. Now, it's time to move on: we're entering a different phase. 
The example above of Gabriela was one of the five cases that were created as part of this research study. Based on synthesis of all five cases, the final synthesis, the play, was created.

\section{Creating the Final Synthesis}

In order for the reader to understand how the final synthesis was created, a brief description is provided below. The final synthesis, which is in the form of a dramatic play, (see https://voices.no/index.php/voices/article/downloadSuppFile/924/290 ) came into being as I was immersed in the data and developing each individual Portrait Synthesis relative to the data collected from each participant. In order to analyze and synthesize the data across cases, and represent the findings, I decided to create a play based on the analysis.

The first step in the final synthesis included a content analysis (Schreier, 2012), which used the combination of concept-driven and data-driven strategies. As described above, the data consisted of the montage portraiture interview visual and textual data, the researcher's memoing and iterative artistic responses, and participant feedback resulting in the creation of the portrait syntheses and then the aggregate final synthesis. During the draft phase of the play, I outlined the structure and sequence of the play. The following concept-driven main categories became the first three acts of the play: Act I sensory-embodied experiences, Act II: relational experiences, and Act III: imaginal experiences. Each act was divided into scenes that correspond to the data-driven themes that emerged during the final synthesis.

Below is the division of acts and scenes.

- Act I: sensory-embodied experiences

- Scene 1: Introduction

- Scene 2: Holding

- Scene 3: Breast feeding

- Scene 4: Connected as one organism

- Scene 5: Pregnancy

- Scene 6: The baby is an ocean

- Act II: Relational experiences

- Scene 1: Introduction

- Scene 2: Breast-feeding tied in with the relationship

- Scene 3: One-way relationship vs reciprocated relationship

- Scene 4: Connection with the baby

- Scene 5: Relationship evolves over time

- Scene 6: Coping with stressors of adjustment

- Scene 7: Joy in the relationship

- Act III: Imaginal experiences

- Scene 1: Introduction

- Scene 2: Fantasy of returning to a former life

- Scene 3: Awareness of darker fantasies

- Scene 4: Positive fantasies for the future

Participant Feedback. Another aspect of the research data that contributed to the formation and interpretation of the final synthesis was the participant feedback. As described earlier, after creating each Portrait Synthesis, I shared it with the participants and asked them for feedback. The participants provided in depth and insightful feedback that added to the existing data. The feedback was synthesized and added to the play as the 4th act.

Visual component of the play. The Final Synthesis also included a visual component. As described previously, five individual Portrait Syntheses had been created. As part of the final synthesis I decided to aggregate the five Portrait Syntheses illustrating the across case comparison and evolving group portrait narrative. Based on the scenes in the draft play, I revisited the scanned images of the individual portrait syn- 
theses in order to locate the visual representations that pertained to the categories and evolving dialogue in these scenes for each participant and between the participants. These group portrait syntheses were aligned with and positioned within the categorical scenes and were then assembled into a slideshow to be shown during the actual reading of the play.

Setting of the play. After I had drafted the play and planned the sequence of the slideshow, the question of the setting of the play emerged. Because this is an arts-based research study, the findings are represented artistically. The participants, of course, never met in real life but in the play they appear to be talking to each other. This raised the need to create a setting in which these five women could come together, and several options were considered. At this point, I asked for and received valuable guidance from my dissertation advisor. After a fruitful discussion with her, I decided that the play be set in an artist's studio. The main argument in favor of this setting was the fact that the researcher, not the actual participants, created the featured artwork. It then became apparent that the researcher, too, should be a participant in the play, acting as the portraitist.

The portraitist's voice. Another question that arose was that of the portraitist's voice. In keeping with the pluralistic intersubjective ontological perspective for this study, the data generated and the interpretation of the data, and the formulation of the results were all co-constructed. Therefore the portraitist's voice is integral to all phases of the study. As part of the data generation, I had created artistic responses and written memos and observations in response to the participants' data and data generation process. These artistic responses had helped me create each individual Portrait Synthesis. For the Final Synthesis, as the artistic components of the individual portraits were incorporated, it seemed inevitable that the researcher's voice should also be present in the Final Synthesis. Interacting with the research participants, and later creating artwork made me personally present with the participants and the research process. In my presence, the participants were exploring and making meaning of their experiences, exposing their doubts and insecurities. In response, those meetings evoked memories, associations, and countertransference in me that I recorded in written memos (Gemignani, 2011). And thus, I could not be just a quiet observer but that my voice should also be heard, therefore, I added myself as a character in the final synthesis and based on my reflexive memos, shared some of my own thoughts, reactions, and observations.

The portrait syntheses as well as the final dramatic synthesis were presented to an audience of graduate students and staff at Drexel University. The portrait syntheses were presented in the form of an exhibition, and volunteer members of the audience read the final dramatic synthesis, the play. It is important for the reader to understand how the mother's beyond_words experiences were represented, staying true to the data, yet holistically and engagingly representing their experiences so that the viewer can LIVE the meaning of the beyond_words phenomena. Typical, textual, linear description alone cannot do justice to the beyond_words phenomena that are non-discursive, multidimensional, and poetic. The arts-based representations require that the viewer experientially engages with the artwork that is essential comprehending the full impact of the beyond_words phenomena. In order to guide the reader to reflect on and engage with the play, the reader might consider the following questions that were also presented to the audience members for their feedback:

1. What did you learn about the beyond_words phenomena that mothers experience in their transition to motherhood?

2. How has this research impacted your attitude and empathy towards first-time mothers?

3. In what way might accessing the results from this research be useful to first-time mothers, mothers-to be and/or art therapists or other clinicians who work with new mothers? 
4. Did you experience any emotional responses? Which feelings did this research evoke in you?

5. Were there any particular parts in the play that evoked emotions or sensations?

6. What personal images or experiences did this research evoke in you? Please reminiscence on any personal memories that came to mind.

If you would like to share your own responses to these questions with us, we would appreciate it! You may contact the corresponding author, Victoria Scotti, by e-mail: victoriascotti@gmail.com

Audience feedback. Audience feedback was the final step in the research. In artsbased research, the presentation of the results often is in the form of exhibitions or performance of the artistic results in a public forum as a method for further assessing the authenticity and credibility of the results. For that purpose, collecting and analyzing audience feedback in this study was implemented as a credibility and authenticity measure. After witnessing the Portrait Synthesis and the reading of the play, the audience members were asked to fill out anonymous feedback questionnaires.

The objectives of the questionnaire were to assess 1) usefulness of research, and 2) aesthetic power of the research which are among two most often used constructs used to evaluate the authenticity and credibility of arts based research (Chilton \& Leavy, 2014; Cole \& Knowles, 2008; Leavy, 2015).

The audience members described that the arts-based experience was useful in communicating a dynamic and interactive expression conveying the simultaneity of emotional, physiological, social, and spiritual dimensions of transitioning to motherhood. This experience, they said, could be useful for healthcare providers, family members, and friends to increase empathy, communication, and preparation for motherhood. The aesthetic power of the performance and the art referred to the engagement with audience through the authentic evocation of visceral experiences, memories, emotions, and personal associations, which contributed to understanding and usefulness. One audience member described "the sense of blending, overlapping of a myriad of emotions and sensations. I really felt that I was witnessing/experiencing the intersubjective relationship between mother, child, and father." Another audience member reported that the experience was "Very powerful. The artwork made me feel, at once, light and heavy at the same time." Overall, the audience feedback was a testament to the aesthetic power of the arts based results relative to its contribution to insight, empathy, emotional resonance, and transferability to real life situations.

\section{Conclusion}

In summary, this arts-based research study engaged new mothers in a process of expressing and conveying their beyond_words experiences of transitioning to motherhood through their textual and artistic expressions. These textual and artistic expressions were then systematically and rigorously analyzed using the researcher's intentional arts based processes that incorporated data from participants' interviews, arts processes, researcher arts based and textual memos, participant feedback, arts based responses, constructions, and synthesis. Arts based research was selected for this study because of both its alignment with beyond_words phenomena and its disseminative impact. By hearing each amplified voice in the associated narratives, and experiencing their interactive dialogue in the play, the viewer can relate to the holistic existential beingness and experience of these mothers which otherwise may not have been conveyed through more traditional research or text.

\section{References}

Afoakwah, G., Smyth, R., \& Lavender, T. (2013). Women's experiences of breastfeeding: A narrative review of qualitative studies. African Journal of Midwifery and Women's Health, $7(2), 71-77$. 
Alter-Muri, S. (2007). Beyond the face: Art therapy and self-portraiture. The Arts in Psychotherapy, 34(4), 331-339.

Barone, T., \& Eisner, E. W. (Eds.). (2012). Arts based research. Thousand Oaks, CA: Sage.

Brilliant, R. (2002). Portraiture. London, UK: Reaktion Books.

Chilton, G., \& Leavy, P. (2014). Arts-based research practice: Merging social research and the creative arts. In P. Leavy (Ed.), The Oxford handbook of qualitative research (pp. 404-422). New York, NY: Oxford University Press.

Chilton, G., Gerber, N., \& Scotti, V. (2015). Towards an aesthetic intersubjective paradigm for arts-based research: An art therapy perspective. UNESCO Observatory Multidisciplinary Journal in the Arts, 5, 1-27.

Cole, A. L., \& Knowles, J. G. (2008). Arts-informed research. In J. G. Knowles \& A. L. Cole (Eds.), Handbook of the arts in qualitative research: Perspectives, methodologies, examples, and issues (pp. 55-70). Los Angeles, CA: Sage Publications.

Costello-Du Bois, J. (1989). Drawing out the unique beauty: Portraits. Art Therapy: Journal of the American Art Therapy Association, 6(2), 67-70, http://dx.doi.org/10.1080/ 07421656.1989.10758868.

Cowdery, R. S., \& Knudson-Martin, C. (2005). The construction of motherhood: Tasks, relational connection, and gender equality. Family Relations, 54, 335-345.

Crossley, M. (2009). Breastfeeding as a moral imperative: An autoethnographic study. Feminism \& Psychology, 19(1), 71-87, http://dx.doi.org/10.1177/0959353508098620.

Darvill, R., Skirton, H., \& Farrand, P. (2010). Psychological factors that impact on women's experiences of first-time motherhood: a qualitative study of the transition. Midwifery, 26(3), 357-366, https://doi.org/10.1016/j.midw.2008.07.006.

Fahey, J. O., \& Shenassa, E. (2013). Understanding and Meeting the Needs of Women in the Postpartum Period: The Perinatal Maternal Health Promotion Model. Journal of Midwifery \& Women's Health, 58(6), 613-621, https://doi.org/10.1111/jmwh.12139.

Freeland, C. (2010). Portraits and persons: A philosophical inquiry. New York, NY: Oxford University Press.

Fish, B. (2012). Response art: The art of the art therapist. Art Therapy: Journal of the American Art Therapy Association, 1, 22-25, http://dx.doi.org/10.1080/07421656.1983.10758734.

Gemignani, M. (2011). Between researcher and researched: An introduction to countertransference in qualitative inquiry. Qualitative Inquiry, 17(8), 701-708, http://dx.doi.org/10.1177/1077800411415501.

Halifax, N. V. D. (2003). Feminist art therapy: Contributions from feminist theory and contemporary art practice. In S. Hogan (Ed.), Gender issues in art therapy (pp. 31-45). London and Philadelphia: Jessica Kingsley Publishers.

Hanes, M. (2007). "Face-to-face" with addiction: The spontaneous production of self-portraits in art therapy. Art Therapy: Journal of the American Art Therapy Association, 24(1), 33-36.

Kapitan, L. (2010). Introduction to art therapy research. New York, NY: Routledge/Taylor \& Francis Group.

Lawrence-Lightfoot, S. (2005). A dialogue between art and science. Qualitative Inquiry, 11(1), 3-15.

Lawrence-Lightfoot, S., \& Davis, J. H. (1997). The art and science of portraiture. San Francisco, CA: Jossey-Bass.

Lintott, S., \& Sander-Staudt, M. (Eds.). (2011). Philosophical inquiries into pregnancy, childbirth, and mothering: Maternal subjects. New York, NY: Routledge.

Leavy, P. (2015). Method meets art (2nd ed.). New York,NY: Guilford.

Leavy, P. (2009). Method meets art. New York, NY: Guilford.

McGann, E. (2006). Color me beautiful: Racism, identity formation, and art therapy. Journal of Emotional Abuse, 6(2-3), 197-217.

McNiff, S. (2008). Art-based research. In A. L. Cole \& J. G. Knowles (Eds.), Handbook of the arts in qualitative research (pp. 29-40). Thousand Oaks, CA: Sage Publications, Inc. 
Nelson, A. (2006). A metasynthesis of qualitative breastfeeding studies. Journal of Midwifery and Women's Health, 51(2), e13-e20.

Or, M. B. (2010). Clay sculpting of mother and child figures encourages mentalization. The Arts in Psychotherapy, 37(4), 319-327, https://doi.org/10.1016/j.aip.2010.05.007.

Prinds, C., Hvidt, N. C., Mogensen, O., \& Buus, N. (2014). Making existential meaning in transition to motherhood: A scoping review. Midwifery, 30, 733-741.

Razurel, C., Bruchon-Schweitzer, M., Dupanloup, A., Irion, O., \& Epiney, M. (2011). Stressful events, social support and coping strategies of primiparous women during the postpartum period: A qualitative study. Midwifery, 27(2), 237-242.

Schmied, V., \& Lupton, D. (2001). Blurring the boundaries: breastfeeding and maternal subjectivity. Sociology of Health and Illness, 23(2), 234-250, https://doi.org/10.1111/ 1467-9566.00249.

Schreier, M. (2012). Qualitative content analysis in practice. Thousand Oaks, CA: SAGE.

West, S. (2004). Portraiture. New York, NY: Oxford University Press. 